\title{
Phenolic Constituents of Vaccinium Species from Both Natural Resources and Micropropagated Plantlets
}

\author{
Mustafa Cüce (Di),1, Tuba Bekircan (D)2, Atalay Sökmen (iD-4
}

${ }^{1}$ Giresun University, Şebinkarahisar School of Applied Sciences, Department of Food Technology, Giresun, Turkey

${ }^{2}$ Eurasia University, Faculty of Science and Art, Department of Biochemistry, Trabzon, Turkey

${ }^{3}$ Konya Food and Agricultural University, Faculty of Natural Science, Department of Plant Production and Technologies, Konya, Turkey

${ }^{4}$ King Saud University, College of Science, Department of Zoology, Riyadh, Saudi Arabia

\begin{abstract}
Fruits and leaves of Vaccinium species have rich bioactive phytochemicals. These bioactive phytochemicals make these plants particularly valuable for the medical and food industry. This novel approach was designed to determine the phenolic content of Vaccinium species obtained from both micropropagated and naturally growing leaves. An efficient micropropagation protocol was developed to produce tree Vaccinium species plantlets via direct organogenesis. Lateral buds containing one or two leaves were cultured in McCown woody plant medium (WPM), supplemented with zeatin/indole-3butyric acid (IBA) (1.0/0.1 $\left.\mathrm{mg} \mathrm{L}^{-1}\right)$. In conclusion, Protocatechuic acid, Chlorogenic acid, Syringic acid and Routine phenolic compounds were determined in significant amounts. It has been determined that the phenolic compounds of leaves produced in tissue cultures is higher than the phenolic compounds obtained from naturally growing leaves.
\end{abstract}

\section{ARTICLE HISTORY}

Received: 18 July 2018

Revised: 19 September 2018

Accepted: 29 October 2018

\section{KEYWORDS}

HPLC,

Phenolic compounds, Micropropagation,

Vaccinium

\section{INTRODUCTION}

Secondary metabolites are important compounds that human beings frequently use especially in the medical field. The development of new and effective production methods leading to these valuable compounds has gained momentum in recent years [1, 2]. Vaccinium species L., belonging the family Ericaceae, is an economically most important wild plant species growing in indigenous population of Turkey. The genus Vaccinium is represented by four species in the Turkish flora, namely Vaccinium uliginosum L., Vaccinium arctostaphylos L., Vaccinium myrtillus L., and Vaccinium vitis-idaea L., and their fruits are consumed by local people as dry or fresh fruit, marmalade, jam, compote, etc. The leaves of Vaccinium species

CONTACT: Mustafa Cüce $\square$ mustafacuce@windowslive.com $\equiv$ Giresun University, Şebinkarahisar School of Applied Sciences, Department of Food Technology, Giresun, Turkey 
have antioxidants and antibacterial properties as well as rich phenolic content. The leaves of these plant species have also been consumed as a herbal tea in the past [3, 4].

Because of these biological benefits, there is a growing interest in Vaccinium species, and many researchers study the commercial cultivation of these species. Due to the many advantages, including a mass effective clonal propagation, a fully controlled environment, a shortened growth cycle, an uninterrupted production process, and production of disease-free plants, plant tissue culture techniques have recently been preferred for the propagation of these species [5-8].

Collection of such valuable plants directly from natural population causes negative effects on natural habitats of plants and serious reductions in plant numbers; however, with plant tissue cultures, it is possible to prevent the use of natural plants for that purpose and keep nature's beauty intact $[9,10]$. An also the micropropagation technique is useful for the production of active compounds during formation of secondary metabolites in medicinal and aromatic plants and in particular, to increase the levels of some important metabolites $[11,12]$. The purpose of this novel study was to develop an efficient and rapid micropropagation protocol for producing Vaccinium plantlets and thereafter compared their phenolics contents with naturally growing plants.

\section{MATERIALS and METHODS}

\subsection{Plant Material}

Actively growing young Vaccinium nodal segments were collected from the natural populations of different regions of Trabzon in 2013. Lateral buds were washed with tap water for $1 \mathrm{~h}$, and then surface sterilized with $70 \%(\mathrm{v} / \mathrm{v})$ ethanol for $1 \mathrm{~min}$, followed by 15 (10 min for $V$. uliginosum explants) min of incubation in 3\% sodium hypochlorite $(\mathrm{NaOCl})$. Finally, they were washed with sterile distilled deionized water 3 times for $15 \mathrm{~min}$. Sterilized explants dried on sterile whatman filter paper and cultured on approximately $50 \mathrm{~mL}$ of nutrient media in $98.5 \times 59 \mathrm{~mm}$ glass containers. Each treatment was performed in triplicates and 30 explants were used for each treatment.

\subsection{Experimental}

For shoot multiplication, McCown woody plant medium including vitamins (WPM) [13], suplemented with zeatin/ indole-3-butyric acid (IBA) $\left(1.0 / 0.1 \mathrm{mg} \mathrm{L}^{-1}\right)$, was used to obtain in large quantities number of plants. WPM basal medium containing $2 \%$ sucrose and $0.8 \%$ agar. Zeatin and IBA used in the study were sterilized with $0.22-\mu \mathrm{m}$ filters and added to the cooled media after autoclaving. The medium $\mathrm{pH}$ was adjusted to 5.0 before autoclaving. Cultures were incubated in a growth chamber maintained at $24 \pm 2{ }^{\circ} \mathrm{C}$ under a $16 / 8$-h day and light conditions. A subculturing protocol was performed every 8 weeks. The regeneration ability of cultures was then evaluated on the basis of mean number of shoots per explant, length of shoots emerged from each explant, mean number of nodes, fresh and dry weight. Each experiment was repeated in triplicate.

\subsection{Extraction}

In vitro grown biomass was extracted as reported elsewhere [14, 15]. Briefly, $200 \mathrm{mg}$ of each sample was macerated in n-hexane (HE) and dichloromethane (DCM) (10 mL_each) for $10 \mathrm{~min}$, solvent was filtered out and residue was removed via methanol $(\mathrm{MeOH})$ extraction for $30 \mathrm{~min}$, and methanol was evaporated in vacuo. The obtained methanol extract was then dipped in $\mathrm{pH} 2.0 \pm 0.1$ water and shaken vigorously followed by extraction three times with $5 \mathrm{~mL}$ diethyl ether and ethyl acetate. Organic phases were combined, evaporated and made up in methanol $(2.0 \mathrm{~mL})$ for HPLC analysis after passing through $0.45 \mu \mathrm{m}$ filter. Determination of 
total phenolic contents were determined with previously reported method [16]. Briefly, $750 \mu \mathrm{L}$ of Folin-Ciocalteu's/water mixture $(1: 14)$ were added to $50 \mu \mathrm{L}$ sample and after $3 \mathrm{~min}, 200 \mu \mathrm{L}$ of $20 \% \mathrm{Na} 2 \mathrm{CO} 3$ was added. Then the reaction mixture was incubated in dark for $30 \mathrm{~min}$. Absorbance was measured on an ultraviolet-visible (UV-Vis) spectrophotometer (Unicam UV2-100) at $760 \mathrm{~nm}$ and methanol was used as blank. Gallic acid was used as standard and total phenol contents in extracts were calculated as mg gallic acid equivalent total phenolic in mg Gallic Acid Equivalent/100 (GAEq mg/100 gm) gm dry weight of plant.

\subsection{HPLC analysis of phenolic compounds}

A previously developed and validated HPLC method [16] was used in the quantification of phenolics. The analysis was carried out on an ELITE LaChrome (Hitachi HPLC system), quaternary pumps (L-2130 model), auto injector (model L-2200) and variable wavelength PDA detector (photo diode array (L-2455 Model). A C-18 reverse phase column $(250 \mathrm{~mm} \times 4.6 \mathrm{~mm}$ id, $5 \mu \mathrm{m}$ particle size, Agilent (USA)) was used in the analysis which was fixed in column oven (Model-2300). Mobile phase was a mixture of solvent A (2\% acetic acid in water) and solvent B (70:30, acetonitrile/water). The injection volume was $20 \mu \mathrm{L}$ and column was kept at $30{ }^{\circ} \mathrm{C}$. The flow rate was kept constant at $1 \mathrm{~mL} \mathrm{~min}^{-1}$ using gradient programming; starting the flow of mobile phase as B (5\%) to three min, gradual increase (up-to 15, 20, 25, 40 and $80 \%$ at 8 , $10,18,25$ and $35 \mathrm{~min}$, respectively) and drop back to $5 \%$ at $40 \mathrm{~min}$ and left for $10 \mathrm{~min}$ to equilibrate in column. Eluent was continuously monitored through PDA by measuring at three different wavelengths, i.e., 280, 315 and $350 \mathrm{~nm}$.

\subsection{Statistical Analysis}

Each treatment included 6 Magenta B-caps (each containing 5 explants) and each was carried out in triplicate for shoot multiplication. All data were analyzed using SPSS 21.0 (IBM Corp., Armonk, NY, USA). The data collected for mean shoot length, mean number of shoots, mean number of nodes for shoot multiplication, fresh and dry weight were analyzed using analysis of variance (ANOVA) with Pearson's correlation. Values are means \pm standard deviation.

\section{RESULTS and DISCUSSION}

\subsection{Shoot Multiplication}

Three different assessed Vaccinium species also improved in the WMP medium supplemented with zeatin/IBA. All Vaccinium species have higher shoot regeneretion frequency (90\%). The highest shoot multiplication was obtained in V.arctostaphylos with 5.08 shoots per explant. Although V. myrtillus and V. uliginosum gave the close shoot multiplication values, there was also a statistically significant difference between these species $(\mathrm{P} \leq 0.05$, Table 1). In recent years, the production of secondary metabolites has been accelerated by tissue culture methods, and many researchers have reported many studies on the production of these valuable metabolites $[1,2,17,18]$. In addition, although there are many studies to determine the secondary metabolite content of Vaccinium species fruits naturally growing in our country [19-22], there isn't any study to compare phenolic contents of Vaccinium species from both natural resources and micropropagated plantlets. Although researchers have found different results depending on the species studied with different media and plant growth regulators [23, $24]$ in terms of shoot number, the most effective results have been obtained from studies using zeatin $[8,25]$.

Our preliminary studies show us, multiplication depends not only on the presence or absence of the growth regulators but the basal medium and the plant species to be reproduced also has a great impact on micropropagation. The highest shoot length was again obtained from V.arctostaphylos with $44.60 \mathrm{~mm}$. This value is higher than the shoot length obtained from $V$. 
myrtillus and V. uliginosum, with $12.31 \%$ and $21.57 \%$, respectively. Moreover, remarkable statistical differences was also established between these three Vaccinium species in terms of the shoot length $(\mathrm{P} \leq 0.05$, Table 1$)$. Unlike the shoot length, a different result was obtained between the three species in terms of the number of nodes. No significant difference was found between $V$. arctostaphylos and $V$. myrtillus in regard with the node number. The highest node number was obtained from $V$. arctostaphylos and V. myrtillus with 12.38 and 12.12 per shoot, respectively. This value was determined at 11.00 in $V$. uliginosum (Table 1). Well-developed plantlets production are needed in the production with micropropagation. Because of this, many researchers have applied different plant growth regulators on the micropropagation of depending on the plant species [26, 27]. Some of these researchers were reported that zeatin is more effective than other cytokinins in terms of the shoot length of Vaccinium species [6]. Also some other researchers were also reported that zeatin was more effective on shoot length than other cytokinins on $V$. uliginosum and $V$. arctostaphylos in terms of the shoot length $[8,28]$. The findings obtained from previous reports support the our findings.

In such biomass studies where the secondary compounds are sought to be obtained, fresh and dry weight findings have also great significance. In this context, the fresh and dry weights of the plant leaves obtained by natural and micropropagation were calculated. The higher fresh and dry weight parameters were achieved from collected natural plant leaves with 1.88 and 0.38 , respectively. These findings were higher than $V$. arctostaphylos with $12.23 \%$ and $18.42 \%$, V. myrtillus with $25 \%$ and $34.21 \%$, and $33.51 \%$ and $50.00 \%$, respectively. Above mentioned, natural collection methods are likely to impact negatively on the natural habitat of these plants and lead to a dramatic decrease in plant populations. Therefore, it is important to carry out studies to obtain valuable secondary products using the advantages of plant biotechnology. This study is the first report to investigate the phenolic content of Vaccinium leaves produced in tissue cultures. Naturally collected Vaccinium leaves were evaluated as control groups.

\subsection{Determination of Phenolic Contents}

Free phenolics were analyzed by HPLC and the findings were summarized in Table 2. Protocatechuic acid, Chlorogenic acid, Syringic acid and Rutin were calculated significant levels. Protocatechuic acid was highest in micropropagated $V$. myrtillus followed by $V$. arctostaphylos with 2.27 and 1.868. One of the dramatic results was showed from Protocatechuic acid content of natural $V$. myrtillus and $V$. uliginosum leaves and no statistically significant data could be obtained $(\mathrm{P} \leq 0.05$, Table 2$)$. In the Chlorogenic acid contents, a significant increase was observed in the leaves of $V$. arctostaphylos and $V$. myrtillus obtained by micropropagation. Micropropagated $V$. arctostaphylos leaves had $164.09 \%$ more Chlorogenic acid content than natural $V$. arctostaphylos leaves and there was a significant statistical difference between them $(\mathrm{P} \leq 0.05)$. A similar condition has also occurred for $V$. myrtillus and this ratio was calculated as $180.98 \%$ (Table 2). The lowest Chlorogenic acid content was achieved from micropropagated $V$. uliginosum with 1.62. 
Table 1. Effect of zeatin in the presence of IBA $\left(0.1 \mathrm{mg} \mathrm{L}^{-1}\right)$ on shoot multiplication of three Vaccinium species.

\begin{tabular}{lllllll} 
& $\begin{array}{l}\text { PGRs } \\
\text { Concentration } \\
\left(\mathrm{mg} \mathrm{L}^{-1}\right)\end{array}$ & $\begin{array}{l}\text { Number of Shoots/ } \\
\text { per Explant }\end{array}$ & $\begin{array}{l}\text { Shoot Length } \\
(\mathrm{mm})\end{array}$ & $\begin{array}{l}\text { Node Numbers/ } \\
\text { per shoot }\end{array}$ & $\begin{array}{l}\text { Fresh Weight } \\
(\mathrm{mg})\end{array}$ & $\begin{array}{l}\text { Dry Weight } \\
(\mathrm{mg})\end{array}$ \\
\hline Natural & - & - & - & - & $1.88 \pm 0.21 \mathrm{a}$ & $0.38 \pm 0.032 \mathrm{a}$ \\
V. arctostaphylos & $1.0 / 0.1$ & $5.08 \pm 0.48 \mathrm{a}$ & $44.60 \pm 2.47 \mathrm{a}$ & $12.38 \pm 0.91 \mathrm{a}$ & $1.65 \pm 0.20 \mathrm{~b}$ & $0.31 \pm 0.039 \mathrm{~b}$ \\
V. myrtillus & $1.0 / 0.1$ & $3.86 \pm 0.51 \mathrm{~b}$ & $39.11 \pm 1.62 \mathrm{~b}$ & $12.12 \pm 0.67 \mathrm{a}$ & $1.41 \pm 0.07 \mathrm{c}$ & $0.25 \pm 0.036 \mathrm{c}$ \\
V. uliginosum & $1.0 / 0.1$ & $3.46 \pm 0.54 \mathrm{c}$ & $34.98 \pm 1.51 \mathrm{c}$ & $11.00 \pm 0.99 \mathrm{~b}$ & $1.25 \pm 0.16 \mathrm{~d}$ & $0.19 \pm 0.011 \mathrm{~d}$ \\
\hline
\end{tabular}

Data were recorded 8 weeks after the culture with a total of 3 replicates of 20 plants per treatment for shoot regeneration. Values having the same letter(s) in the same column are not significantly different according to Duncan's multiple range test at $\mathrm{P} \leq 0.05$. PGRs: Plant Growth Regulators

Table 2. Phenolics identified of Vaccinium species from both natural resources and micropropagated plantlets though HPLC (mg/100 g)

\begin{tabular}{|c|c|c|c|c|c|c|}
\hline & \multicolumn{3}{|l|}{ NATURAL } & \multicolumn{3}{|c|}{ MICROPROPAGATED } \\
\hline & $\begin{array}{l}V . \\
\text { arctostaphylos }\end{array}$ & $\begin{array}{l}V . \\
\text { myrtillus }\end{array}$ & $\begin{array}{l}V . \\
\text { uliginosum }\end{array}$ & $\begin{array}{l}V . \\
\text { arctostaphylos }\end{array}$ & $\begin{array}{l}V . \\
\text { myrtillus }\end{array}$ & $\begin{array}{l}V . \\
\text { uliginosum }\end{array}$ \\
\hline Protocatechuic acid & $1.752 \pm 0.097 \mathrm{~b}$ & - & - & $1.868 \pm 0.017 b$ & $2.27 \pm 0.17 \mathrm{a}$ & $1.29 \pm 0.0 \mathrm{c}$ \\
\hline Chlorogenic acid & $7.52 \pm 0.61 \mathrm{~d}$ & $47.15 \pm 1.70 b$ & $133.85 \pm 5.16 \mathrm{a}$ & $19.86 \pm 0.45 \mathrm{c}$ & $132.48 \pm 0.88 \mathrm{a}$ & $1.62 \pm 0.18 \mathrm{e}$ \\
\hline Syringic acid & $0.608 \pm 0.077 \mathrm{~d}$ & $0.63 \pm 0.038 \mathrm{~d}$ & $0.97 \pm 0.091 \mathrm{c}$ & $1.72 \pm 0.14 \mathrm{a}$ & $1.42 \pm 0.08 \mathrm{~b}$ & $0.66 \pm 0.07 \mathrm{~d}$ \\
\hline Rutin & $2.998 \pm 0.012 \mathrm{a}$ & - & - & - & - & - \\
\hline
\end{tabular}

Data were recorded 8 with a total of 3 replicates. Values having the same letter(s) in the same line are not significantly different according to Duncan's multiple range test at $\mathrm{P}$ $\leq 0.05$. 
The importance of the study has emerged with the identified secondary compounds, which are predominantly high in micropropagated plants. Syringic acid content was also found to be higher in micropropagated plantlets than in natural ones except for again $V$. uliginosum. Rutin was calculated only natural sample of $V$. artostaphylos and amount of it was determined as 2.998. Although many researchers have mostly studied the biologically active components of Vaccinium fruits [29-31], very few researchers have studied on natural leaves of these valuable plants $[32,33]$. In one of the these studies researchers performed such a study on Vaccinium angustifolium and reported that tissue culture techniques enhance the total phenolic contents of $V$. angustifoliumum [34]. The same researchers have reported that tissue culture technique used in the study can affect the phenolic content. Similarly, the other some researchers have reported that chlorogenic acid myricetin, syringic acid and rutin are main phenolic components of micropropagated blueberry seedlings [35]. These researchers have specified that micropropagated Vaccinium seedlings are a good source of antioxidant compounds in terms of the above mentioned phenolic compounds. These results also support our findings.

\section{CONCLUSION}

This study emphasized to determined efficient in vitro micropropagation method and to compare of phenolic compounds of micropropagated Vaccinium plantlets and natural ones. At this occasion, phenolic contents of natural Vaccinium leaves and micropropagated seedlings of three Vaccinium species growing in the Turkish flora compared for the first time. According to the results, there were significant increases in some phenolic compounds in micropropagated seedlings of some species. Some factors such as the type of plant species, the type of medium and the type and combination of plant growth regulator can affect these desired outcomes. The efficient results of these valuable plant species may be a pioneer of scientific reports and it may lead the way to enhance the further multidisciplinary experiments.

\section{Conflict of Interest}

The authors declare that there is no conflict of interests in this current study.

\section{Acknowledgement}

The authors deeply appreciate the financial support of KTÜ-BAP (the Scientific Research Committee of Karadeniz Technical University) and the Ministry of Science, Industry, and Technology for projects KTÜ-BAP-2009.111.004.5 and 0360.TGSD.2011, respectively.

\section{ORCID}

Mustafa CÜCE (DiD https://orcid.org/0000-0001-7406-171X

Tuba BEKİRCAN (D) https://orcid.org/0000-0003-1954-297X

Atalay SÖKMEN (D) https://orcid.org/0000-0002-2206-7906

\section{REFERENCES}

[1] Cüce, M., Bekircan, T., Laghari, A. H., Sökmen, M., Sökmen, A., Uçar, E. Ö. \& Kılıç, A. O (2017b). Antioxidant phenolic constituents, antimicrobial and cytotoxic properties of Stachys аппиа L. from both natural resources and micropropagated plantlets. Indian Journal of Traditional Knowledge, 16(3), 407-416.

[2] Bekircan, T., Yaşar, A., Yıldırım, S., Sökmen, M. \& Sökmen, A. (2018). Effect of cytokinins on in vitro multiplication, volatiles composition and rosmarinic acid content of Thymus leucotrichus Hal. shoots. 3 Biotech, 8(3), 180.

[3] Vučic', D. M., Petkovic', M. R., Rodic' -Grabovac, B. B., Stefanovic', O. D., Vasic', S. M. \& $\mathrm{C}^{\circ}$ omic', $^{\prime}$ L. R. (2013). Antibacterial and antioxidant activities of bilberry (Vaccinium myrtillus L.) in vitro. African Journal of Microbiology Research, 7(45), 5130-5136. 
[4] Bujor, O. C., Le Bourvellec, C., Volf, I., Popa, V. I. \& Dufour, C. (2016). Seasonal variations of the phenolic constituents in bilberry (Vaccinium myrtillus L.) leaves, stems and fruits, and their antioxidant activity. Food chemistry, 213, 58-68.

[5] Ostrolucká, M. G., Libiaková, G., Ondrušková, E. \& Gajdošová, A. (2004). In vitro propagation of Vaccinium species. Acta Universitatis Latviensis ser. Biology, 676, $207-$ 212.

[6] Meiners, J., Schwab, M. \& Szankowski, I. (2007). Efficient in vitro regeneration systems for Vaccinium Species. Plant Cell, Tissue and Organ Culture, 89, 169-176.

[7] Cüce, M. \& Sökmen, A. (2015). Micropropagation of Vaccinium myrtillus L. (bilberry) naturally growing in the Turkish flora. Turkish Journal of Biology, 39, 233-240.

[8] Cüce, M. \& Sökmen, A. (2017a). In vitro production protocol of Vaccinium uliginosum L. (bog bilberry) growing in the Turkish flora. Turkish Journal of Agriculture and Forestry, 41(4), 294-304.

[9] Lucchesini, M. \& Mensuali-Sodi, A. (2010). Plant tissue culture-An opportunity for the production of nutraceuticals. Advances in Experimental Medicine and Biology, 698, 185202.

[10] Ruffoni B., Pistelli, L., Bertoli, A. \& Pistelli, L. (2010). Plant Cell Cultures: Bioreactors for Industrial Production. Advances in Experimental Medicine and Biology, 698, 203-221.

[11] Arikat N. A., Jawad F. M., Karam N. S. \& Shibli, R. A. (2004) Micropropagation and accumulation of essential oils in wild sage (Salvia fruticosa Mill.). Scientia HorticulturaeAmsterdam, 100, 193-202.

[12] Pistelli, L., Giovannini, A., Ruffoni, B., Bertoli, A. \& Pistelli, L. (2010). Hairy root cultures for secondary metabolites production. Advances in Experimental Medicine and Biology, 698, 167-184.

[13] Lloyd G, McCown B (1980). Commercially-feasible micropropagation of mountain laurel (Kalmia latifolia) by use of shoot tip culture. Combined Proceedings, International Plant Propagators' Society, 30: 421-427.

[14] Ma, Y-Q., Chen, J-C., Liu, D-H. \& Ye, X-Q. (2009). Simultaneous extraction of phenolic compounds of citrus peel extracts: Effect of ultrasound. Ultrasonics Sonochemistry, 16, 57-62.

[15] Kim, K-H., Tsao, R., Yang, R., \& Cui, S.W. (2006) Phenolic acid profiles and antioxidant activities of wheat bran extracts and the effect of hydrolysis conditions. Food Chemistry, 95, 466-473.

[16] Singleton, V. L. \& Rossi, J. A. (1965). Colorimetry of total Phenolics with phosphomolybdic phosphotungstic acid reagents. American Journal of Enology and Viticulture, 16, 144-158.

[17] Rao, S. R., \& Ravishankar, G. A. (2002). Plant cell cultures: chemical factories of secondary metabolites. Biotechnology Advances, 20(2), 101-153.

[18] Amoo, S. O., Aremu, A. O., \& Van Staden, J. (2012). In vitro plant regeneration, secondary metabolite production and antioxidant activity of micropropagated Aloe arborescens Mill. Plant Cell, Tissue and Organ Culture (PCTOC), 111(3), 345-358.

[19] Ayaz, F. A., Hayirlioglu-Ayaz, S., Gruz, J., Novak, O. \& Strnad, M. (2005). Separation, characterization, and quantitation of phenolic acids in a little-known blueberry (Vaccinium arctostaphylos L.) fruit by HPLC-MS. Journal of Agricultural and Food Chemistry, 53(21), 8116-8122

[20] Primetta, A. K., Jaakola, L., Ayaz, F. A., Inceer, H., \& Riihinen, K. R. (2013). Anthocyanin fingerprinting for authenticity studies of bilberry (Vaccinium myrtillus L.). Food Control, 30(2), 662-667. 
[21] Colak, N., Torun, H., Gruz, J., Strnad, M., Subrtova, M., Inceer, H., \& Ayaz, F. A. (2016a). Comparison of phenolics and phenolic acid profiles in conjunction with oxygen radical absorbing capacity (ORAC) in berries of Vaccinium arctostaphylos L. and V. myrtillus L. Polish Journal of Food and Nutrition Sciences, 66(2), 85-92.

[22] Colak, N., Torun, H., Gruz, J., Strnad, M., Hermosín-Gutiérrez, I., Hayirlioglu-Ayaz, S. \& Ayaz, F. A. (2016b). Bog bilberry phenolics, antioxidant capacity and nutrient profile. Food chemistry, 201, 339-349.

[23] DiZhou, G., HanDong, G., MeiYing, G., JunYi, Z. \& YunTian, J. (2009). In vitro culture and plant regeneration system of Vaccinium uliginosum, Forest Research, Beijing, 22, 226-229.

[24] Litwińczuk, W. 2013. Micropropagation of Vaccinium sp. by in vitro axillary shoot proliferation methods, Molecular Biology, 11013, 63-76.

[25] Debnath, S. C. \& McRae, K. B. (2001b). In vitro culture of lingonberry (Vaccinium vitisidaea L.) the influence of cytokinins and media types on propagation. Small Fruits Review, 1(3), 3-19.

[26] Ružić, D., Vujović, T., Libiakova, G., Cerović, R. \& Gajdošova, A. (2012). Micropropagation in vitro of highbush blueberry (Vaccinium corymbosum L.). Journal of Berry Research, 2, 97-103.

[27] Paprštein, F. \& Sedlák, J. (2015) In vitro multiplication of lingonberry - short communication. HortScience, 42, 102-106.

[28] Cüce, M., Bektaş, E. \& Sökmen, A. (2013). Micropropagation of Vaccinium arctostaphylos L. via lateral-bud culture. Turkish Journal of Agriculture and Forestry, 37, 40-44.

[29] Lätti, A. K., Kainulainen, P. S., Hayirlioglu-Ayaz, S., Ayaz, F. A. \& Riihinen, K. R. (2009) Characterization of anthocyanins in Caucasian blueberries (Vaccinium arctostaphylos L.) native to Turkey. Journal of Agricultural and Food Chemistry, 57(12), 5244-5249.

[30] Lee, J. \& Finn, C. E. (2012). Lingonberry (Vaccinium vitis-idaea L.) grown in the Pacific Northwest of North America: Anthocyanin and free amino acid composition. Journal of Functional Foods, 4(1), 213-218.

[31] Oszmiański, J., Kolniak-Ostek, J., Lachowicz, S., Gorzelany, J. \& Matłok, N. (2015). Effect of dried powder preparation process on polyphenolic content and antioxidant capacity of cranberry (Vaccinium macrocarpon L.). Industrial Crops and Products, 77, 658-665.

[32] Martz, F., Jaakola, L., Julkunen-Tiitto, R. \& Stark, S. (2010). Phenolic composition and antioxidant capacity of bilberry (Vaccinium myrtillus) leaves in Northern Europe following foliar development and along environmental gradients. Journal of Chemical Ecology, 36(9), 1017-1028.

[33] Wang, L., Xu, H. N., Yao, H., and Zhang, H. (2011). Phenolic composition and radical scavenging capacity of Vaccinium bracteatum Thunb. leaves. International Journal of Food Properties, 14(4), 721-725.

[34] Goyali, J. C., Igamberdiev, A. U. \& Debnath, S. C. (2013). Morphology, phenolic content and antioxidant capacity of lowbush blueberry (Vaccinium angustifolium Ait.) plants as affected by in vitro and ex vitro propagation methods. Canadian Journal of Plant Science, 93(6), 1001-1008.

[35] Contreras, R. A., Köhler, H., Pizarro, M. \& Zúiga, G. E. (2015). In vitro cultivars of Vaccinium corymbosum L. (Ericaceae) are a source of antioxidant phenolics. Antioxidants, 4(2), 281-292. 